\title{
Do ensino da gramática à prática de análise linguística: o ponto e a segmentação textual na escrita de jovens e adultos
}

\author{
Cláudia Aparecida Ferreira Ferrazi (UFJF) \\ Natália Sathler Sigilianoii (UFJF)
}

\begin{abstract}
Resumo:
Neste artigo, será apresentada a análise do uso do ponto em produções escritas de alunos do $4^{\circ}$ período da Educação de Jovens e Adultos (EJA). Tal análise visa a entender de que maneira é realizada a segmentação textual por meio da pontuação e ainda verificar em que medida uma intervenção pedagógica em sala de aula de língua portuguesa sob o viés da análise linguística (MENDONÇA, 2006) pode auxiliar os alunos na construção efetiva dos sentidos de um texto. Adotando-se os postulados de Dahlet (2006) para a pontuação, busca-se compreender os usos do ponto como totalizador de uma informação no continuum da escrita e a apropriação pelos alunos de EJA dessas estratégias de uso após movimentos de ação-reflexão-ação, pautados na pesquisa-ação (THIOLLENT, 1986). Os resultados da análise apontam para a efetividade da intervenção pedagógica realizada em sala de aula, destacando a importância da prática de análise linguística como uma perspectiva exitosa para o ensino de pontuação.
\end{abstract}

Palavras-chave: Ensino de Língua Portuguesa; Análise Linguística; Pontuação; Ponto; Segmentação Textual.

Abstract: In this article, we analyze the use of full stops in written

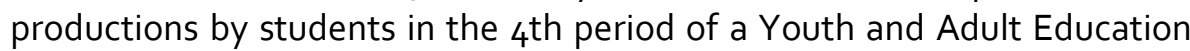
Program (EJA). Such an analysis focuses on the way students segment texts using punctuation as well as asses to what extent a Linguistic Analysis-based (MENDONÇA, 2006) pedagogical action in a Portuguese Language class improves the students' ability to effectively produce meaning in texts. Following Dahlet (2006), we seek to understand (a) the uses of the full stop as an information totalizer in the writing continuum of writing and (b) the mastering of those uses by EJA students after the action-reflection-action movements, based on the research in action methodology (THIOLLENT, 1986). The results point to the effectiveness of the pedagogical action carried out, highlighting the role of Linguistic Analysis as a successful option for teaching punctuation. 
Keywords: Portuguese Language Teaching; Linguistic Analysis; Punctuation; Full Stop; Text Segmentation.

\section{Introdução}

A despeito de todas as mudanças efetivadas no ensino de Língua Portuguesa nas últimas décadas no país, o trabalho com a gramática nas salas de aula continua, por vezes, revelando práticas tradicionais de ensino, pautando-se por uma visão estruturalista na qual se privilegiam regras e nomenclaturas em detrimento de uma reflexão consciente acerca dos fenômenos linguísticos que ocorrem em nossa prática social, tendo o texto como objeto de estudo (MENDONÇA, 2006). Sigiliano \& Silva (2017), em pesquisa empreendida com o intuito de analisar a aderência ou não das práticas de análise linguística ( $A L$ ) nos livros didáticos aprovados pelo Programa Nacional do Livro Didático para o Ensino Fundamental II, do ano de 2017, constataram que, apesar de o texto ter recebido proeminente espaço no que tange ao estudo de conteúdos gramaticais, ainda nota-se considerável foco da análise pautada em palavras e em frases para o ensino de gramática.

A mesma pesquisa revelou ser a pontuação um conteúdo ainda muito pautado em práticas transmissivas de ensino de língua no ciclo básico. Nessa linha de análise, Ferraz (2018), debruçando-se especificamente sobre o ensino de pontuação na Educação de Jovens e Adultos (EJA), destaca serem as abordagens concernentes à pontuação, nos materiais didáticos voltados para a EJA, também de perfil bastante transmissivo, pautado na normatização de regras verificadas por meio de exemplos do cânone literário ou de frases fora de um contexto de comunicação social.

Tal abordagem, distante do uso linguístico, dificulta, sobremaneira, o uso da pontuação nos textos de alunos em todos os níveis de ensino, o que tem acarretado a utilização desse sistema com parâmetros associados a "certos fenômenos da pontuação oral, sobretudo, à respiração, à entonação e aos movimentos do pensamento" (DAHLET, 2006, p.24).

Considerando o disposto acima, este artigo visa a analisar dados de uso do ponto ${ }^{1}$ em uma turma de Educação de Jovens e Adultos (EJA), $4^{\circ}$ período do Ensino Fundamental

\footnotetext{
${ }^{1}$ Neste trabalho, o termo "ponto" é usado para se referir àquilo que, em algumas gramáticas e livros didáticos, é chamado de "ponto final".
} 
(correspondente ao $9^{\circ}$ ano), em produções escritas. Buscamos entender como o aluno ${ }^{2}$ utilizava o ponto com a função de sequencialização de seu texto, em produção inicial e, posteriormente, após aplicação de uma intervenção pedagógica planejada e realizada sob a perspectiva da prática de análise linguística (MENDONÇA, 2006), de que forma a segmentação ${ }^{3}$ foi alterada. Com essa análise, que é parte de uma intervenção ainda mais ampla realizada nessa sala de aula, intentou-se observar o impacto do ensino renovado de gramática quanto à pontuação. Esta intervenção pautou-se na concepção que trata a linguagem como forma ou processo de interação, em que a linguagem é tomada como "um lugar de interação humana" (GERALDI, 1999, p. 41) no qual os "interlocutores interagem enquanto sujeitos que ocupam lugares sociais" (TRAVAGLIA, 2009, p. 23).

Consideramos, para efeito de análise, o ponto em sua função de sequencialização, buscando compreender como essa pontuação sequencial pode servir para a produção dos sentidos do texto, tendo como base os estudos de Dahlet (2006). Em decorrência, este artigo tem a pretensão de contribuir com o repensar das relações de ensino-aprendizagem da pontuação.

Para desenvolver essa proposta, discute-se, em primeiro lugar, como as pesquisas de Dahlet (2006) compreendem o uso do ponto como uma pontuação sequencial. Em seguida, será apresentado um breve resumo de uma intervenção pedagógica efetivada em sala de aula de $4^{\circ}$ período da EJA, na qual a abordagem da pontuação ocorreu de forma diferenciada em relação aos materiais didáticos comumente voltados para esse perfil, passando a adotar o viés da análise linguística. Tal intervenção ocorreu no ano de 2017, no município de Itamarati de Minas, como parte de pesquisa de Mestrado Profissional em Letras. Por fim, analisaremos os textos produzidos pelos alunos na intervenção, comparando-os às primeiras produções feitas por eles.

Partindo do pressuposto de que a maneira de pontuar é definida pela intenção comunicativa e pela interação estabelecida entre autor/texto/leitor (KOCH \& ELIAS, 2006), levaremos em consideração os aspectos semânticos, sintáticos e pragmáticos que envolvem a utilização da pontuação no texto.

\footnotetext{
${ }^{2}$ As análises foram realizadas em textos dos alunos de uma turma da EJA, cujos dados serão apresentados. No entanto, por conta do espaço deste artigo, será realizado um estudo mais detalhado de dois textos de um único aluno.

3 Segmentação pode ser entendida como o ato de separar, por meio da pontuação, segmentos de texto delimitados à esquerda e à direita por um ponto. Sequência é o segmento delimitado pelo ponto (DAHLET, 2006).
} 


\section{Pressupostos teóricos}

Considerando-se a necessidade de um ensino de gramática renovado, que extrapole a memorização de prescrições exemplificadas em exemplos canônicos, assume-se neste artigo a defesa da prática de análise linguística para o ensino da pontuação, a qual foi seguida na aplicação da intervenção em sala de aula cujos dados serão expostos neste artigo. Segundo Suassuna (2012), o trabalho com a AL em sala de aula deve ter como parâmetro reflexivo alguns conceitos que distinguem diferentes ações de linguagem, descritas como atividades linguísticas, epilinguísticas e metalinguísticas. Ademais, Bezerra \& Reinaldo (2013) recomendam o uso equilibrado dessas ações de linguagem com a finalidade de garantir que o aluno se torne um usuário competente da língua e também detentor de um saber sobre a língua. Sobre a abordagem da AL, Geraldi (1999 [1984]) destaca que:

[...] a prática de análise linguística não poderá limitar-se à higienização do texto do aluno em seus aspectos gramaticais e ortográficos, limitando-se a "correções". Trata-se de trabalhar com o aluno o seu texto para que ele atinja seus objetivos junto aos leitores a que se destina. (GERALDI, 1999 $[1984]$, p. 74)

Portanto, apesar de a análise que será aqui explicitada focar na apresentação de adequação de uso ou não da pontuação em textos dos alunos, será possível observar, em linhas gerais, por meio do Esquema 1, apresentado na seção de Metodologia, que a intervenção envolveu diversas etapas que visavam a explorar os sentidos da pontuação na leitura e na escrita.

Também nesse movimento, a Base Nacional Curricular Comum (BNCC), ao traçar os objetivos para o segundo ciclo do Ensino Fundamental, enfatiza a importância do ensino da $\mathrm{AL}$ :

O trabalho didático de análise linguística [...] se organiza tendo como ponto de partida a exploração ativa e a observação de regularidades no funcionamento da linguagem. Isso é o contrário de partir da definição para chegar à análise (como tradicionalmente se costuma fazer). Trata-se de situações em que se busca a adequação da fala ou da escrita própria e alheia, a avaliação sobre a eficácia ou adequação de certas expressões no uso oral ou escrito, os comentários sobre formas de falar ou escrever, a análise da pertinência de certas substituições de enunciados, a imitação da linguagem utilizada por outras pessoas, o uso de citações, a identificação de marcas da oralidade na escrita e vice-versa, a comparação entre diferentes sentidos atribuídos a um mesmo texto, a intencionalidade implícita em textos lidos ou ouvidos, etc. (BRASIL, 2017, p.54). 
Junto a isso, ressalta-se a escassez de estudos e práticas renovadas associadas à pontuação. Entretanto, apesar de serem relativamente escassos os estudos sobre o sistema de pontuação, conforme constatam Puzzo e Silva (2014), dois entendimentos sobre esse item linguístico se destacam: i) o tratamento da pontuação pelo viés normativo-prescritivo e pelo viés descritivo; ii) os estudos que reconhecem a pontuação como um sistema que "se situa ao lado da escrita e da leitura, isto é, da produção e da recepção de sentido, operando em conjunto para aperfeiçoar a legibilidade e a interpretação" (DAHLET, 2006, p. 23). Levando em conta que este estudo tem o interesse na análise da efetividade de um ensino renovado de gramática (aqui entendido como análise linguística), assume-se ser a pontuação um sistema que "participa do sentido em elaboração no ato da comunicação escrita" (DAHLET, 2006, p. 26).

Dahlet (2006) distingue três níveis de pontuação: pontuação de palavra ${ }^{4}$, pontuação de frase e pontuação de texto5 ${ }^{5}$ O nível de pontuação que nos interessa aqui é a pontuação de frase, definida como "todos os sinais que podem aparecer no nível frasal" (DAHLET, 2006, p. 34). Portanto, o lugar do estudo desse item linguístico é o texto, pois ela se manifesta no "desenrolar efetivo de uma comunicação escrita" (DAHLET, 2006, p. 27).

No nível frasal, a autora distingue duas classes funcionais: a função de sequencialização e a função enunciativa. Definindo "sequência como um segmento de texto" (DAHLET, 2006, p. 50), a autora explica que os sinais com função sequencial "segmentam para retomar o continuum da escrita, delimitam as sequências, reagrupandoas e separando-as, e, por fim, hierarquizam-nas" (DAHLET, 2006, p. 50). Assim, são sinais com função de sequencialização: alínea ${ }^{6}$, ponto, ponto-e-vírgula e vírgula. Como este artigo delimita como campo de estudo o uso do ponto, vamos nos ater ao estudo da função de sequencialização e a forma como esse sinal específico desempenha tal função.

A autora destaca que o uso dos sinais de sequencialização está ligado a uma questão de amplitude. Dessa forma, usa-se um sinal quando outro de mesmo nível ou nível superior não intervém. Além disso, por delimitar o continuum da escrita em segmentos, o uso do ponto, como outros sinais sequenciais, afeta esse continuum. Com isso, torna-se necessário

\footnotetext{
${ }^{4} \mathrm{~A}$ pontuação de palavras, que tem seu domínio na ortografia, não nos interessa nesse estudo.

${ }^{5}$ A pontuação textual é definida como "um conjunto de brancos que dão forma ao texto" (DAHLET, 2006, p. 34), como a alínea, por exemplo.

${ }^{6}$ De acordo com Dahlet (2006), a alínea é responsável por delimitar "um conjunto paragráfico do outro".
} 
estabelecer uma escala de níveis dos sinais permitindo estabelecer uma "ordem hierárquica de inclusão dos segmentos na cadeia" (DAHLET, 2006, p. 56), quais sejam: Nível 1 sequência: parágrafo [alínea........alínea]; Nível 2 - sequência: frase [ponto..................ponto]; Nível 3: sequência: subfrase \{ponto-e-vírgula...... ponto-e-vírgula]; Nível 4 - sequência: inter-oracional [vírgula........vírgula]; Nível 5 - sequência: intra-oracional [vírgula.....vírgula] (cf. DHALET, 2006).

Faz-se relevante destacar que, no nível 2, pode-se usar sinais de amplitude equivalente, quais sejam: ponto de exclamação, ponto de interrogação e reticências, além de se esperar o uso da maiúscula como sinal indicativo de início de segmento nesse nível. Dahlet (2006) enfatiza ainda que é sempre possível um sinal de nível maior (excetuando-se o nível 1) substituir um sinal de nível menor. Esse alerta é importante no caso, por exemplo, de substituição de vírgula pelo ponto, principalmente em textos literários.

Como um sinal sequencial de amplitude de nível 2, o ponto, nas gramáticas, tem a função de encerrar, concluir ou terminar uma frase ou um período (cf. DAHLET, 2006). Mas, o que determina, de fato, o uso do ponto? Para Dahlet (2006), é necessário que se conceitue, a priori, frase.

A autora compreende frase como um conceito gramatical e linguístico que nos remete, na escrita, a uma realização efetiva, ou seja, de segmentação do discurso em unidades gráficas. Dessa forma, Dahlet define a frase como "o segmento limitado à esquerda e à direita por um ponto (ou por qualquer equivalente paradigmático, ou seja, de mesma amplitude: pontos de interrogação, de exclamação e reticências)" (DAHLET, 2006, p. 127). Segue, assim, o critério de frase como uma delimitação gráfica pertencente ao domínio do escrito que se associa a uma ação linguageira específica. A frase é, portanto, unidade de pontuação. Referenciando-se em Berrendonner (1993), Dahlet (2006) explica que o autor:

Ao definir a frase como unidade de pontuação e, portanto, unidade gráfica, ele a introduz de início no domínio do escrito, o qual fica tratado na sua vertente discursiva e comunicacional. É na regulagem desses dois parâmetros (segmentação e produção discursiva e comunicacional) que se torna possível dar conta da heterogeneidade do fenômeno. (DAHLET, 2006, p. 128)

Observamos que a autora apresenta um conceito mais amplo de frase que se constitui de elementos in praesentia que estabelecem a ligação e elementos in absentia 
ligados à memória discursiva. Desta forma, Dahlet destaca: "(a) a primazia da definição tipográfica da frase sobre qualquer outra, e (b) o fato de que é imprescindível integrar, para o entendimento da frase, a dimensão enunciativa de ação linguageira, que parece ser o parâmetro primeiro para a delimitação do segmento" (DAHLET, 2006, p. 132).

Levando-se em consideração a variação pontuacional existente, Dahlet (2006) entende que há parâmetros que regulam essa variação, sendo que, no caso do ponto são: o sentido (sentido referido - construção semântico-referencial, e o sentido visado - intenção de comunicação que pode modificar o sentido referido), a intenção de comunicação e a legibilidade. Dessa forma, o ponto limita tanto à esquerda quanto à direita a unidade gráfica frase, marcando o lugar de ocorrência da totalização inferencial, no qual o leitor deve, utilizando-se de sua competência interpretativa, concluir a unidade informacional ancorada naquela unidade gráfica (DAHLET, 2006, p. 250).

Em sua função sequencial, o ponto é responsável pela segmentação frasal, à qual se circunscreve ao menos uma unidade comunicacional não-decomponível em unidades menores de mesmo nível (DAHLET, 2006, p. 131). A força de segmentação do ponto no continuum da escrita é melhor percebida e estudada no texto, lugar da pontuação, de acordo com Dahlet, sendo esta a posição assumida na intervenção pedagógica realizada e na análise dos dados que serão apresentados neste artigo.

\section{Metodologia}

Conforme disposto acima, a análise de uso do ponto em produções de alunos de EJA pautou-se em intervenção pedagógica aplicada no $4^{\circ}$ Período da Educação de Jovens e Adultos, da cidade de Itamarati de Minas, Minas Gerais, no ano de 2017. A turma contava com alunos de distintas faixas etárias, provenientes da zona rural e urbana, e era composta de trabalhadores braçais (pedreiros, serventes e lavradores), além de costureiras, donas de casa e jovens estudantes. Tal intervenção foi motivada pela ausência total de sinais de pontuação ou uso desordenado deles nas produções dos alunos, de forma a prejudicar a construção dos sentidos dos textos.

Essa intervenção buscou contribuir para o letramento dos alunos da EJA, visto que houve reflexão e ação sobre o uso da língua, articulando os eixos da leitura, da produção e da análise linguística. Além disso, a intervenção pedagógica oportunizou o contato da turma com o suporte jornal e com os gêneros que o compõem, por meio do estudo de 
textos, da reflexão sobre os sinais de pontuação e outros itens linguísticos que emergem dos gêneros estudados e da produção textual, que culminou na publicação de um jornal editado pela turma. Todo o processo reflexivo assumiu o texto como ponto de partida e de chegada. A cada análise e nova observação quanto ao uso da pontuação, os alunos eram convidados a sistematizar as constatações em um quadro individual organizado pela professora e disponibilizado aos alunos.

Apesar de a intervenção ter abarcado diversos sinais de pontuação, este artigo intenta mostrar como esse ensino renovado auxiliou os alunos na conscientização da importância do uso do ponto para a construção dos sentidos do texto como um sinal importante de sequencialização textual.

Tendo em vista esse viés investigativo e a estreita associação com a ação em sala de aula com base em um problema coletivo diagnosticado e, ainda, a relevância da cooperação e da participação dos sujeitos docente e discentes na resolução da questão, adotou-se o procedimento da pesquisa-ação (THIOLLENT, 1986). Essa metodologia permite a contínua observação da sala de aula em que o professor atua e, ao mesmo tempo, a aplicação de uma prática em sala de aula objetivando o aprimoramento das abordagens de ensino. Essa intervenção, que teve a duração de quatro meses e envolveu a exploração de todos os tipos de pontuação, possibilitou a reorientação do ensino do ponto por um processo constante de ação-reflexão-ação e, em linhas gerais, foi realizada contando com três etapas, as quais são resumidas no Esquema 1.

Por razões do objetivo deste artigo, não serão descritas todas as ações envolvidas na intervenção. Cabe destacar a primeira e algumas ações da primeira e da segunda etapas.

A intervenção pedagógica envolveu, em sua primeira etapa, intitulada Ponto de Partida, a produção de um gênero oral, a piada. A docente solicitou que os alunos se organizassem em duplas e que registrassem por áudio do aplicativo de celular Whatsapp a piada que o colega contaria, sabendo que estas piadas seriam retextualizadas em um texto escrito e veiculadas em um livro de piadas a ser distribuído na escola. Essa produção, além de ter sido escolhida devido ao fato de o gênero apresentar ricas possibilidades no trabalho com a oralidade e com a forma de demarcação de sentido no texto por meio da pontuação, foi, em sua versão escrita, utilizada como forma de diagnosticar a maneira como os alunos utilizavam os sinais de pontuação, em especial, para este artigo, do ponto. 
De posse dos dados obtidos por meio das análises iniciais das produções das piadas, a docente verificou novamente a dificuldade dos alunos quanto ao uso adequado da pontuação nas produções de texto e, com isso, preparou semanalmente o material didático a ser aplicado nas aulas seguintes, levando em consideração a frequência dos usos da pontuação nas retextualizações e as características do sistema de pontuação que emergem dos gêneros estudados (notícia, artigo de opinião, tirinha), os quais foram previamente escolhidos pelos alunos. Dessa forma, foram elaboradas sequências de atividades para o estudo de cada um dos gêneros, aliando a prática de análise linguística ao estudo dos textos e articulando a leitura à produção escrita.

A estrutura modular de cada sequência de atividades contribuiu para a reflexão linguística, epilinguística e metalinguística sobre as implicações sintáticas e semânticopragmáticas da pontuação. Cada módulo de estudo do gênero apresentava a seguinte estrutura: Ação 1 - introdução, em que era apresentada a motivação da seção e as interpretações de imagens relacionadas à temática que seria abordada no capítulo didático; Ação 2 - reconhecimento do gênero (leitura em grupo de textos pertencentes ao gênero estudado); Ação 3 - estudo sobre os aspectos composicionais e a materialidade linguística dos textos, com destaque para o uso da pontuação e suas característica aplicadas ao gênero estudado, realizado por meio de material didático preparado pela professora; Ação 4 sistematização do estudo da pontuação, realizada por meio de preenchimento de um quadro preparado pela professora a fim de que cada aluno fizesse as suas anotações de suas reflexões acerca da função de cada topograma estudado; Ação 5 - produção do gênero, que envolveu planejamento, escrita, revisão feita pelos pares, revisão juntamente com a docente, reescrita e publicação em jornal editado pela turma no final do período interventivo.

As atividades de análise linguística, presentes no material didático elaborado pela professora, buscavam despertar nos alunos as estratégias metacognitivas de análise e avaliação consciente da materialidade linguística e especialmente compreender os efeitos de sentido particulares de cada gênero, advindos da escolha do uso da pontuação. Dessa forma, cabia ao aluno, a partir do texto e com a mediação da docente, compreender, por exemplo, os efeitos de sentido e as diferentes funções que as aspas poderiam assumir em uma notícia estudada ou compreender como era efetivada pelo autor do texto a sequência das informações dadas por meio do topograma de amplitude 2 - o ponto. Tais atividades 
foram baseadas em textos reais, como notícias veiculadas em jornais de amplitude nacional e jornais regionais.

O processo de reflexão presente em cada estudo procurou guiar o aluno no sentido de compreender o uso dos sinais de pontuação. Em cada atividade feita, os alunos eram instigados a perceber a regularidade do sinal nos gêneros estudados. Quando a regularidade era identificada e reconhecida pelos alunos, a turma preenchia uma tabela com as funções de cada topograma compreendido. Assim, no caso do ponto, por exemplo, os alunos registraram que ele é responsável por fechar uma frase com uma informação completa ou implícita.

Ao final de todas as etapas, foi realizada uma comparação entre as sistematizações feitas em sala de aula pelos alunos e as regras de pontuação presentes na gramática tradicional. As reflexões resultantes dessa comparação apontaram para a percepção de que o uso superou as regras, notando-se, portanto, uma extrapolação de funcionalidades da pontuação em situações de uso, se comparadas àquilo que é normatizado, por exemplo, ao se analisar a função da pontuação em textos ou gêneros específicos. Essa percepção foi importante para os alunos porque se conscientizaram de sua capacidade e importância de refletir sobre a língua em textos que circulam em nossa sociedade. 


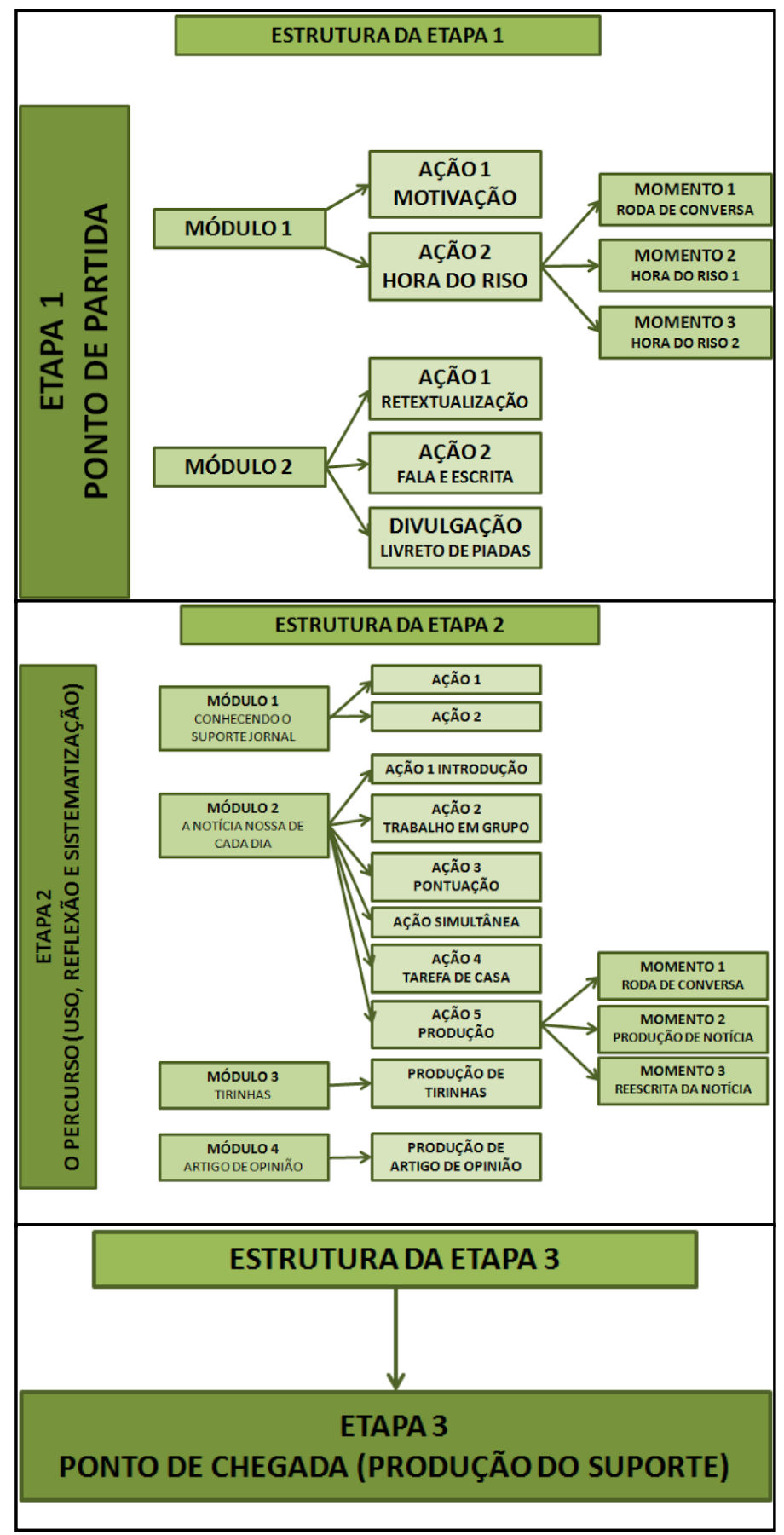

Esquema 1: Estrutura das etapas da intervenção pedagógica (FERRAZ, 2018, p. 87, 92, 97)

As reflexões acerca do uso da pontuação também foram realizadas durante a reescrita do texto em questionamentos feitos pelos próprios alunos e por meio de perguntas da docente que levavam o aluno a refletir sobre suas escolhas quanto a determinados topogramas.

Após extensas reflexões sobre a pontuação na leitura e na escrita (envolvendo parte das etapas 1 e 2), os alunos foram convidados a redigir uma notícia que seria publicada em 
um jornal da turma, a circular pela cidade em que a escola se insere. A produção desta notícia também foi alvo da análise de dados, como forma de se perceberem os ganhos dos alunos no processo de ensino-aprendizagem da pontuação.

Para tanto, foram analisadas as produções de texto dos alunos da turma de forma individualizada e, por fim, de forma contrastiva, com o intuito de se observarem os avanços alcançados por meio da aplicação de um material e de aulas pautadas na perspectiva da AL. Dessa forma, vale destacar ainda que o corpus estudado foi constituído por produções de texto em número diversificado, visto que os alunos de EJA, no início da intervenção, ainda se revelavam como discentes faltosos. Como se trata de alunos "flutuantes", para o primeiro momento, a análise foi realizada em um total de seis produções escritas (retextualizações de piadas) e, para o segundo momento, de dez produções (notícias).

Na próxima seção, serão apresentados e discutidos os dados e exemplos do corpus.

\section{Análise de dados}

Tal qual sinalizado na metodologia, as análises de dados foram realizadas com base nos textos dos alunos, produtos da intervenção realizada na EJA, e serão apresentadas da seguinte maneira: num primeiro momento, será analisado o uso do ponto em retextualizações de piadas produzidas pelos alunos; em um segundo momento, traremos as análises das produções de notícias e, ao final, será traçado um comparativo entre as duas produções, a fim de se concluir de que maneira o uso deste sinal de pontuação demonstra a compreensão por parte dos alunos do ponto como um sinal sequencial.

\subsection{Análise do uso do ponto empregado na retextualização de piadas}

As retextualizações analisadas a seguir foram elaboradas em sala de aula como atividade introdutória da intervenção pedagógica. Tal atividade serviu como um diagnóstico, dando suporte à professora para a elaboração de material didático de estudo do gênero notícia, visando a ressaltar o uso da pontuação nesse gênero.

A análise seguiu os seguintes critérios: presença do ponto no texto (mesmo com uso que não auxiliava na sequencialização do texto); ausência do ponto (marcadamente aquela verificada por prejuízo semântico e de conexão entre as partes do texto); uso adequado; uso inadequado, que pode ser gerado pelo uso de um sinal de pontuação de amplitude menor 
ao ponto [,] e [;] ou os dois-pontos em cotexto dialogal; inconstância no uso, marcadamente naqueles textos em que o aluno assinalava com ponto para demarcar sequencialização e em outro momento, não realizava essa marcação. Tais critérios serão expostos em um quadro e, posteriormente analisados, mais detidamente, com excertos dos seis textos produzidos em sala de aula.

Ao proceder à análise, foi possível perceber que o ponto foi o segundo sinal de pontuação mais ausente nas retextualizações. Essa constatação é perceptível pois a ausência prejudica o continuum da escrita, afetando a construção dos sentidos do texto. Abaixo, reproduzimos a Tabela 1 que demonstra a frequência de uso de ponto quantificada por aluno:

\begin{tabular}{|c|c|c|c|c|c|}
\hline $\begin{array}{c}\text { Sinais de } \\
\text { Pontuação }\end{array}$ & $\begin{array}{c}\text { Total de } \\
\text { Alunos }\end{array}$ & $\begin{array}{c}\text { Uso } \\
\text { Adequado }\end{array}$ & $\begin{array}{c}\text { Uso } \\
\text { Inadequado }\end{array}$ & $\begin{array}{c}\text { Inconstância } \\
\text { no Uso }\end{array}$ & $\begin{array}{c}\text { Ausência do } \\
\text { Sinal }\end{array}$ \\
\hline Ponto & 3 & 1 & 0 & 2 & 3 \\
\hline
\end{tabular}

Tabela 1: Frequência de uso ou ausência de sinais de pontuação quantificados por aluno (adaptada de FERRAZ, 2018, p. 107)

Como se pode obervar, dos seis alunos que realizaram a produção escrita da piada, a metade usou o ponto em seu texto e a outra metade não utilizou. Dos três que o utilizaram, apenas um fez uso adequado e dois foram inconstantes, denotando que em alguns momentos conseguiam realizar a sequencialização do texto por meio do uso do ponto e, em outros momentos, não conseguiam construir sentidos por meio da função sequencial deste sinal. Como se pode verificar no texto abaixo:

Eu comprei um cavalo $\varnothing$ (1) ele era casado $\varnothing$ (2) ai um certo dia $\otimes$ (3) ele estava caminhando pela cidade pela cidade $\varnothing(4)$ enfim $\otimes(5)$ entrou numa rossa $\varnothing(6)$ so que nessa rossa tinha uma pata $\varnothing(7)$ e pata u parou e falou assim $\otimes(8)$ cavalo o senhor aceitaria se casa comigo $\otimes(9)$ ele falou $\otimes$ (10) não posso minha pata $\otimes(11)$ eu já tenho quatro patas $\varnothing$ (12)

Retextualização de Piada - Aluno 3 (FERRAZ, 2018, p. 114)

As marcas $\varnothing$ e $\otimes$ foram usadas no texto para demarcar a ausência do ponto e de outros sinais de pontuação (como vírgula, dois pontos e interrogação, por exemplo), respectivamente, em momentos em que eles poderiam ocorrer. As numerações foram inseridas a fim de facilitar a análise que será apresentada. Percebe-se que o continuum da escrita foi prejudicado pela falta de sequencialização, devido à ausência do ponto. O texto em questão é semanticamente interpretável com algum esforço do leitor que busca atribuir 
sentidos e fazer a sequência textual a seu modo, sem a interferência do autor, o que prejudica o estabelecimento.

Cabe destacar que, em alguns momentos, o uso do ponto poderia ser substituído por um sinal de amplitude menor, como a vírgula ou o ponto-e-vírgula, que entram em sistema com o ponto "por manifestar na cadeia sintagmática a maneira como aquele que escreve entrosa a informação" (DAHLET, 2006, p.136). No entanto, aqui opta-se pelo uso do ponto por este preencher um papel significativo na hierarquização dos níveis de amplitude de uso, levando em consideração que "a amplitude de um topograma pára onde intervém um topograma de mesmo nível ou de nível superior" (DAHLET, 2006, p. 56). No caso do ponto, o único topograma de nível superior é a alínea.

Em "Eu comprei um cavalo $\varnothing$ (1) ele era casado $\varnothing(2)$ ai um certo dia $\otimes(3)$ ele estava caminhando pela cidade pela cidade $\varnothing(4)$ enfim $\otimes(5)$ entrou numa rossa $\varnothing(6)^{\prime \prime}$, observa-se que o aluno deixou de fazer seis marcações de pontuação de sequencialização (no caso, o ponto e a vírgula). É possível dizer que a segmentação da frase deve ser feita com o fechamento de uma unidade informacional que comporta, pelo menos, uma unidade comunicação. É função do ponto anunciar essa totalização "pelo fato de que se acrescenta, à direita do sinal, um segmento que se liga sintática e semanticamente à informação que precede" (DAHLET, 2006, p. 251). Dessa forma, o enunciado acima apresenta quatro informações diferentes que devem ser limitadas por esse topograma: i) em 1, a compra do cavalo pelo sujeito enunciador; ii) a informação de que esse cavalo era casado, em 2; iii) a inserção da informação de que o cavalo andava pela cidade, em 4 ; iv) e, finalmente a informação de que ele entrou em uma roça, em 6 . Tais informações necessitam ser segmentadas por meio do ponto. Apesar de reconhecer o uso hierarquizador do ponto, nesse contexto, dependendo da reorganização da escrita, o texto comportará um topograma de amplitude menor, como a vírgula por exemplo. Ou, em determinados casos, a inserção da conjunção " $e$ " precedida de pontuação zero, desempenhando a função de coordenar dois segmentos. Os casos em que a conjunção "e"pode ser usada com sinais sequenciais à sua esquerda não serão tratados neste artigo. Há ainda no enunciado a necessidade de uso de um sinal de sequencialização intracláusulas, a vírgula, nas posições 3 e 5, por se tratar de um topograma de valor hierárquico inferior cuja função é por em espera "um ou vários segmentos, em razão do não fechamento do sentido" (DAHLET, 2006, p. 152). Mais abaixo, há a transcrição de uma reescrita que faz uso da vírgula e da conjunção 
"e" com o objetivo de agregar cláusulas e adiar a completude sintático-semântica, efetivada pelo ponto.

Ainda considerando o uso do ponto, temos o seguinte enunciado: "so que nessa rossa tinha uma pata". Aqui, eliminando a marca de oralidade "só que", obtém-se uma frase delimitada à esquerda e à direita, necessariamente, por um ponto. Consequentemente, o enunciado seguinte abre uma nova sequência, na qual a pata conversa com o cavalo, iniciando um diálogo cuja pontuação em cotexto dialogal também foi ignorada, quais sejam: [:], [,], [-], [?], [!]. Assim, pode-se observar: ausência dos dois pontos nas posições 8 e 10; ausência do ponto de interrogação na posição 9; ausência do ponto na posição 11, que pode ser substituído por um ponto de exclamação por se tratar de topograma de amplitude equivalente ao ponto; ausência do ponto de exclamação na posição 12, que também pode ser substituído pelo ponto, dependendo do sentido que se deseja construir para o texto. $E_{\text {, }}$ ainda, espera-se o uso da "maiúscula como sinal indicativo do início do segmento de nível 2" (DAHLET, 2006, p. 57).

Podemos afirmar ainda que é sempre possível usar um sinal de amplitude maior em lugar de outro de amplitude menor, em uma das extremidades do segmento. Trata-se da aplicação da "lei da exclusão de um sinal por outro, a qual, na categoria dos sinais de sequência, ocorre sempre em proveito de um sinal de maior amplitude" (DAHLET, 2006, p. 58), excetuando, nesse caso, o nível 1, por ter uma amplitude superior à dos demais sinais de pontuação.

Abaixo, transcrevemos o texto após reflexões sobre o emprego da pontuação e a produção de sentido e a reescrita do Aluno 3:

Eu comprei um cavalo. Ele era casado.

Certo dia, ele estava caminhando pela cidade e entrou numa roça. Nessa roça, tinha uma pata.

Ela o parou e falou assim:

- Cavalo, o senhor aceitaria se casar comigo?

Ele respondeu:

- Não posso, minha pata. Eu já tenho quatro patas!

Reescrita da retextualização de piada - Aluno 3 (FERRAZ, 2018, p. 114)

Como afirma Dahlet (2006), o uso do ponto, por ser um sinal sequencial, afeta o continuum da escrita delimitando os segmentos, reagrupando-os ou separando-os. Com o uso do ponto, verificado acima, estabelecem-se limites à esquerda e à direita, formando uma sequência carregada de sentido. Findada a sequência de atividades com o gênero 
piada, que culminou na publicação do livro, passou-se, na etapa 2, ao trabalho com o suporte jornalísitico e com os gêneros que nele figuram. A próxima seção analisa os dados obtidos na atividade de produção do gênero notícia.

\subsection{Análise do uso do ponto empregado na notícia}

O corpus dessa análise é constituído de dez textos de alunos do $4^{\circ}$ período da EJA, pertencentes ao gênero notícia, produzidos em sala de aula. Por ser um gênero cujas pontuações específicas se limitam ao uso de ponto, vírgulas, dois pontos, aspas e parênteses, e pelo fato de o texto ter sido produzido após estudo interventivo do item linguístico pontuação em notícias de jornal, hipotetizava-se alcançar um resultado que revelasse a conscientização dos alunos em relação ao uso do ponto mais especificamente. Nesses termos, encontramos os resultados expressos na Tabela 2:

\begin{tabular}{|c|c|c|c|c|}
\hline $\begin{array}{c}\text { Sinais de } \\
\text { Pontuação }\end{array}$ & $\begin{array}{c}\text { Frequência nos } \\
\text { Textos }\end{array}$ & $\begin{array}{c}\text { Uso } \\
\text { Adequado }\end{array}$ & Uso Inadequado & $\begin{array}{c}\text { Ausência do } \\
\text { Sinal }\end{array}$ \\
\hline Ponto & 43 & 39 & 4 & 19 \\
\hline
\end{tabular}

Tabela 2: Frequência de uso e distribuição dos sinais de pontuação nos textos dos alunos (produção de notícia) (adaptada de FERRAZ, 2018, p.140)

O primeiro resultado obtido com a análise foi de que os topogramas usados pelos alunos coincidiam com aqueles característicos do gênero. Esse foi o primeiro aspecto positivo. Ademais, a frequência de uso do ponto aumentou significativamente, o que parece ter ocorrido por dois motivos: i) o gênero notícia demanda um uso maior do sinal analisado; ii) houve uma consciência maior da necessidade do uso da pontuação a fim de separar o texto em segmentos significativos formando o continuum da escrita.

Destacamos o segundo motivo como o mais provável já que um texto de extensão maior (como é o caso da notícia comparada às piadas anteriormente produzidas) e de maiores possibilidades de uso de sinal também oferece maiores possibilidades de equívocos na construção da segmentação e, consequentemente, do continuum.

Assim, foi possível observar 43 usos desse topograma, sendo 39 usos adequados, de forma a contribuir com os sentidos e apenas 4 com usos inadequados. Ainda foram encontradas 19 ausências desse sinal, que podem ser explicadas pela dificuldade que os alunos dessa turma ainda apresentavam em produzir um texto adequado à modalidade 
escrita, visto ainda associarem a noção de pontuação à marcação de entonação e pausas motivadas tão somente por fatores típicos da oralidade, como a respiração.

Destacamos a troca desse topograma por outro sinal de amplitude menor como a vírgula e os dois pontos. Dahlet (2006) afirma que é sempre possível um sinal de amplitude equivalente ([?], [!], [...]) substituir um sinal das extremidades de um segmento (ponto). Afirma, ainda, que é sempre possível um sinal de nível maior substituir um sinal de nível menor de amplitude. No texto abaixo, o aluno faz a substituição de um sinal de amplitude menor por um de amplitude maior. Esse fato demonstra a tomada de consciência do aluno da necessidade do uso de um sinal naquele determinado lugar, mesmo fazendo escolhas equivocadas.

A fim de elucidar a apropriação dos alunos quanto ao uso do ponto, analisar-se-á a notícia produzida pelo Aluno 3, o mesmo que não empregou sinais de pontuação na produção inicial apresentada neste artigo. Leia-se a notícia:

\section{HOMÉM ENFURÉCIDO MATA JOVEM A TIROS}

No dia 22 de setembro. (1) Um homem discutindo com uma mulher em Santana de Cataguases, atirou nela após ela xinga o rapaz. (2) A moça estava filmando quando tomou o primeiro tiro,(3) o motivo da morte foi quando rapaz estava furiozo com uma outra briga (4) o rapaz estava nervozo com a jovem filmando a briga dele com outra pessoa, e foi tira satisfação com ela foi no momento da raiva.(5) O vídeo que foi gravado esta com a policia civil,(6) eles cuidaram do assunto (7) o rapaz esta prezo, e a mulher morreu no hospital na terça feira dia 26 de setembro.(8)

Produção de notícia - Aluno 3 (FERRAZ, 2018, p. 142)

Ao texto foram acrescidas numerações a fim de guiar a análise que será feita adiante. Cabe ressaltar que o texto analisado demonstra avanços significativos quando comparado à retextualização investigada anteriormente. No primeiro texto não havia um único uso de sinal de pontuação e, particularmente, a ausência do ponto prejudicava a produção de sentidos e progressão textual. Já na notícia reproduzida acima, observa-se o uso dos pontos e das vírgulas delimitando o continuum da escrita em segmentos.

Observa-se um desvio no que se refere à distribuição sistêmica das amplitudes dos sinais, já no início do texto. Em: "No dia 22 de setembro. (1) Um homem discutindo com uma mulher em Santana de Cataguases, atirou nela após ela xinga o rapaz.", temos a troca de um sinal de amplitude nível 4 para um sinal de amplitude superior, nível 2. Nesse caso específico, não há possibilidade de se realizar essa troca pois "No dia 22 de setembro" trata- 
se de uma cláusula7 que faz parte de um período. A sequência entre as cláusulas deve ser marcada com a vírgula ou o ponto-e-vírgula. No caso em questão, cabe o uso de uma vírgula para marcar o deslocamento do adjunto adverbial, terceiro princípio de uso da vírgula, denominado por Dahlet (2006) de princípio da inversão. A passagem da amplitude 4 à amplitude 2 rompe com as regras de ordenação que obedecem a um princípio hierárquico, já que ocorrem duas cláusulas que devem ser segmentadas por uma vírgula, sob pena de dificultar o estabelecimento dos sentidos do período.

Na posição 2 temos: "No dia 22 de setembro. (1) Um homem discutindo com uma mulher em Santana de Cataguases, atirou nela após ela xinga o rapaz.(2)". Diferentemente da posição 1, o aluno conseguiu, com o uso do ponto, dar conta da segmentação de fim de frase, seguida de letra maiúscula. Houve, dessa forma, a observação da amplitude 2 que respeita a hierarquia do uso dos sinais de pontuação com função de sequencialização.

O período "A moça estava filmando quando tomou o primeiro tiro, (3) o motivo da morte foi quando rapaz estava furiozo com uma outra briga (4) o rapaz estava nervozo com a jovem filmando a briga dele com outra pessoa, e foi tira satisfação com ela foi no momento da raiva. (5)" deve ser analisado com atenção.

Para entender quais são as condições que acarretam, no período acima, a ocorrência do ponto é preciso aplicar os planos de análise definidos por Dahlet (2006): "(a) a unidade comunicativa não decomponível em unidade menor e (b) a segmentação gráfica denominada frase, que é delimitada em ambas as extremidades pelo ponto" (DAHLET, 2006, p. 125). A título de complementação da informação, é preciso ter clara a ideia de que é a relação entre esses dois planos que rege a ocorrência do uso do ponto, já que uma frase pode incluir várias cláusulas (unidades comunicativas não decomponíveis).

Analisando o período citado, pode-se identificar três informações básicas que fazem parte de uma sequência, ou seja, do segmento de texto reproduzido acima que pode ser delimitada por vírgulas, ponto-e-vírgulas ou ponto, quais sejam: i) A moça filmava no momento que tomou o primeiro tiro; ii) a moça morreu porque o rapaz estava furioso com outra briga; iii) o rapaz estava nervoso porque a jovem estava filmando a briga dele com outra pessoa. Essas três informações são básicas para o entendimento de que há três segmentações que podem incluir unidades comunicativas não decomponíveis, ou seja, três

\footnotetext{
7 Cláusula é entendida aqui como em Berrendonner (apud DAHLET, 2006) como uma unidade comunicativa que faz parte de um período, ou seja, a totalização de cláusulas.
} 
frases que devem ser delimitadas por um ponto. Dessa forma, compreende-se que, na posição 3, o aluno deveria usar um ponto para delimitar a frase à direita, já que na esquerda havia a delimitação por esse topograma. Há, como se pode observar, um todo comunicativo composto de duas cláusulas. A segunda informação abarca outra frase composta de unidades comunicativas não decomponíveis, sem marcação de pontuação intercláusulas. Deve-se usar apenas o ponto na posição 4, fechando a sequência ou a segmentação de amplitude maior. A não marcação desta posição com um topograma, pelo aluno, pode ser explicada pelo uso de um conectivo cuja relação semântica parece remeter para a continuidade de uma unidade comunicativa. Na posição 5, o topograma finaliza um enunciado semanticamente completo.

Em "O vídeo que foi gravado esta com a policia civil, (6) eles cuidaram do assunto (7) o rapaz esta prezo, e a mulher morreu no hospital na terça feira dia 26 de setembro.(8)", pode-se depreender três informações: i) A polícia civil está com o vídeo gravado com a mulher; ii) a polícia civil cuidou do assunto; iii) o assassino está preso e a mulher morreu no hospital. Por conseguinte, necessariamente, deveria haver três unidades gráficas (frases), três segmentações marcadas com o ponto e seguidas de maiúsculas. Apenas na posição 8 o aluno conseguiu estabelecer o final da sequência, algo que não conseguiu fazer na sua primeira produção. Na posição 6, observa-se que o aluno parece entender o segmento "O vídeo que foi gravado esta com a policia civil, (6)" como uma segmentação intercláusula que deve ser marcada pela vírgula. Na realidade, trata-se de uma frase que necessita ser delimitada por um ponto com a seguinte reescrita: "O vídeo que foi gravado está com a polícia civil. Ela cuidou do assunto. (7)" Pode-se também considerar o enunciado como uma frase apenas, admitindo-se a seguinte reescrita: "O vídeo gravado está com a polícia civil que cuida do assunto.". Nesse último caso, usaríamos apenas o ponto na posição 7 para demarcar a finalização da segmentação.

\section{Resultados}

Como dito anteriormente, "por ser uma segmentação de nível 2 (amplitude imediatamente inferior à da alínea), o ponto anuncia que ali acaba algo e começa algo novo" (DAHLET, 2006, p. 250). Sendo assim, esse topograma se constitui em uma instrução de leitura, ou seja, uma totalidade da informação limitada à direita e à esquerda pelo ponto. 
Compreender e fazer com que os alunos compreendessem essa dinâmica dentro de um texto foi uma das principais tarefas na aplicação da intervenção pedagógica.

Os resultados obtidos por meio da análise dos textos dos alunos permitiu considerar as estratégias e procedimentos de ensino utilizados em sala de aula como exitosos. Além de possibilitar a reflexão linguística consciente sobre o ato de pontuar e o uso dos sinais de pontuação nos diferentes gêneros e diferentes contextos, oportunizou a aplicação dos conhecimentos na produção textual dos gêneros estudados.

Assim, comparando a produção inicial da piada com a notícia produzida pelo aluno, temos os seguintes resultados:

i. Reconhecimento da necessidade de segmentação do texto com auxílio de sinal de pontuação de amplitude 2 [.] ou amplitude 4 [,].

ii. Uso dos sinais de acordo com a característica do gênero produzido.

iii. Uso do ponto como um topograma de função de sequencialização que totaliza uma informação limitando-a à direita e/ou à esquerda.

iv. Compreensão da pontuação como elemento fundamental na construção dos sentidos do texto.

Esses resultados apontam para a reafirmação de que a reflexão linguística, ancorada em gêneros textuais diversos, no ensino dos sinais de pontuação e, especificamente, do ponto em sua função de sequencialização pode fazer mais sentido para o aluno principalmente se as estratégias de ensino articularem leitura, análise linguística e produção escrita, ou seja, tomarem a língua como verdadeiro lugar de interação.

\section{Considerações finais}

Tendo em vista a escassez de estudos sobre o tema no que diz respeito ao ensino de língua portuguesa e ao viés adotado pelos livros didáticos, trabalhar com o item linguístico pontuação não é uma tarefa fácil, caso se assuma um ensino reflexivo sob a perspectiva da análise linguística. Esse ensino que tem o caráter de uma gramática renovada demanda conhecimento linguístico, pesquisa detalhada, atitude autoral para preparar o material didático, criatividade para preparar as estratégias pedagógicas, dedicação e atitude de pesquisador preparado para replanejar, caso haja necessidade. Como os resultados apontam, todo esse empenho tem como consequência a aprendizagem efetiva, comprovada nas produções textuais apresentadas. 
Nossa análise de um topograma específico, o ponto, buscou, investigá-lo dentro de um contexto sintático-semântico e pontuacional no qual se inseria, considerando ainda as substituições possíveis. Levou-se em consideração, para isso, a totalidade informacional (frase) e a amplitude do ponto como um sinal com função sequencial.

Por fim, as análises apresentadas apontam para a necessidade de se trabalhar o entendimento da função de segmentação do ponto e a sua força na totalização informacional de uma unidade gráfica. Essa compreensão passa, necessariamente, pelo estudo do texto. Nesse sentido, diferentemente do que tem ocorrido, este artigo aponta para a necessidade de a pontuação ter o seu lugar de estudo cativo no ensino dos gêneros textuais, em todo o Ensino Fundamental e Médio, por meio de atividades pautadas na análise linguística, como forma de apropriação do uso destes sinais por parte dos alunos.

\section{Referências}

BEZERRA, M. A.; REINALDO, M. A. Análise linguística: afinal, a que se refere? São Paulo: Cortez, 2013.

BRASIL. Ministério da Educação. Base Nacional Comum Curricular - BNCC. Brasília, DF, 2017.

DAHLET, V. As (man)obras da pontuação: usos e significações. São Paulo: Associação Editorial Humanitas, 2006.

FERRAZ, C. A. F. A pontuação e a produção de sentidos: uma proposta interventiva na educação de jovens e adultos. Dissertação (mestrado) - UFJF/Faculdade de Letras/Programa de Mestrado Profissional em Letras, PROFLetras/UFJF, 2018.

GERALDI, J. W. (org.). O texto na sala de aula. 3 ed. São Paulo: Ática, 1999 [1984].

KOCH, I. V. \& ELIAS, V. M. Ler e compreender os sentidos do texto. São Paulo: Contexto, 2006.

MENDONÇA, M. Análise linguística no ensino médio: um novo olhar, um outro objeto. In: C. BUNZEN, \& M. M. [orgs], Português no ensino médio e formação de professor. p. 199226. São Paulo: Parábola Editorial, 2006.

PUZZO, M. B. \& SILVA, A. C. Produtividade, sentido e estilo: pontuação/sintaxe em um poema inédito de Cassiano Ricardo. In: PUZZO, M. B.; KOZMA, E. V. B; UYENO, E. Y. Os sinais de pontuação e seus efeitos de sentido: uma abordagem discursiva. Coleção Novas Perspectivas em Linguística Aplicada. Vol. 39. Campinas: Fontes Editores, 2014.

SIGILIANO, N. S. \& SILVA, W. R. Diagnóstico de propostas de análise linguística em livros didáticos aprovados em programa oficial. In: MAGALHÃES, T. G.; GARCIA-REIS, A. R.; 
FERREIRA, H. M. (orgs) Concepção discursiva de linguagem: ensino e formação docente. Campinas: Pontes Editora, 2017.

SUASSUNA, L. Ensino de análise linguística: situando a discussão. In: SILVA, A.; PESSOA, A. C.; LIMA, A. (orgs.) Ensino de gramática: reflexões sobre a língua portuguesa na escola. Belo Horizonte: Autêntica Editora, 2012.

THIOLLENT, M. Metodologia da pesquisa-ação. São Paulo: Cortez, 1986.

TRAVAGLIA, L. C. Gramática e interação: uma proposta para o ensino de gramática no $1^{\circ} \mathrm{e}$ $2^{\circ}$ graus. 14 ed. São Paulo: Cortez: 2009.

\footnotetext{
'Mestra em Letras (UFJF).

E-mail: claudiaferraz.ita@gmail.com

ii Doutora em Linguística (UFRJ); Professora do mestrado profissional em Letras (UFJF).

E-mail: natalia.sigiliano@ufjf.edu.br
} 